\title{
Incidental and Instructed Vocabulary Acquisitionin L2 Contexts: An Experimental Study
}

\author{
Pushpa Nagini Sripada
}

\author{
Doi:10.5901/mjss.2015.v6n4s1p210
}

\begin{abstract}
Vocabulary teaching is a neglected area even today in India in spite of researchers suggesting that 'knowing more words in a new language is knowing the language better'. A quasi- experimental study was carried out in an Engineering college in India for a sample of sixty students and sixty six in two groups. Two strategies were tried out with one group of participants were exposed to incidental vocabulary learning strategy. The other group was exposed to explicit vocabulary learning strategy. Pretest and post test scores were compared for quantitative data analysis and questionnaire was used for qualitative analysis. Both groups showed improvement in their post-test, but explicit vocabulary learning group scored more in post-test than the incidental vocabulary learning group. The effectiveness of the strategy was tested through $Z$ cal test. The findings show that both groups performed well in their post-test, but the explicit teaching group's post test score was better and the learners also showed more enthusiasm than the incidental vocabulary learning group.
\end{abstract}

Keywords: Incidental learning, explicit teaching, Vocabulary, English as a Second Language, English for Science and Technology, experimental study, experimental study

\section{Importance of Vocabulary Teaching}

'What is new is not true, what is true is not new' this proverb is very much applicable to the history of vocabulary teaching. There were debates that took vocabulary as an aspect of teaching in and out of fashion over the years. Though vocabulary is central to language and words are of critical importance to the typical language learner, teachers and researchers have undervalued the teaching of vocabulary by giving importance to syntax and the phonology in the past.

\section{Review of Literature}

Wilkins' Notional Syllabus (1976) accentuated the importance of focusing on certain kinds of tasks (e.g. affirmation, approval, inducement) rather than merely learning about the structure of the language in a vacuum( Nunan 1988). The lexical content of the notions or functional syllabus would arise from the contexts chosen to illustrate the exponents of the selected functions and notions. In other words, vocabulary was subservient to the other more important elements of learning' and was usually introduced in ways that suited the presentation of grammar or functions, or through texts used for various structural or communicative purposes. Sinclair and Renouf (1998) argue the case for a lexical syllabus based on frequency and concordance data. In essence, they propose that students be taught the words that are used mostly by native speakers and they should be taught in contexts in which they are almost likely to occur. They base their work on the insight that the ten most frequent words in English (the, of, and, to, a, in, that, I, it and was) make up seventeen percent per cent of a typical English text. Lewis (1993) in his Lexical Syllabus lists out ten practical ways in which lexis contributes as a syllabus component:

1. 'Delexical' verbs (e.g. take and have as in take a break and have dinner), prepositions and modal auxiliaries deserve lexical rather than grammatical treatment.

2. Students should be taught more base verbs rather than spend so much time on tense formation( the simple present has a very high frequency compared with other tense forms).

3. There is no need to present systematically dense items in a context. It is better to teach more items.

4. Any content noun should be taught with appropriate verb and adjective collocations.

5. Students should be offered institutionalized sentences to illustrate grammar points. These would both provide the basis for reflection on grammar and would allow the learners to make use of them for communicative activity.

6. Sentence heads, e.g. Do you mind if I or would you like to - should be focused on.

7. An awareness of supra -sentential lexical linking both in spoken and written discourse should be taught.

8. 'Synopsing' verbs -i.e. those we use in summarizing what someone else has said -should be focused on. 
9. Students should be given an awareness of frequently used metaphors like the connection between time and money or between the movement of people or water.

10. Synonyms within the existential paradigm should be taught partly as an example of supra-sentential lexical linking. E.g. Isn't it cold? Or she's absolutely right, isn't she? Yes, she certainly has all my support.

\section{Incidental Leraning and Explicit Teaching}

\subsection{Incidental learning:}

Laufer (1989) explains that incidental learning is not necessarily unconscious subliminal or unattended. It is questionable whether any learning can occur without attention (Schmitt 1994).Incidental learning of information occurs without the intention to learn it, but as a byproduct of another activity which is the learner's main objective. For example, during a reading task, some words may be looked up in the dictionary and subsequently remembered. Similarly if a sentence is written and subsequently the word is remembered, the learning would be incidental. If, on the other hand, the learner made a decision to remember all the words, s/he looked up during the reading task, or while writing a sentence, consequently engaged in committing them to memory, then learning was intentional. The difference between incidental and intentional vocabulary learning lies only in the absence or presence of the intent to learn a word.

In a comprehensive review of research on incidental vocabulary learning in mostly L1 contexts, Krashen (1989) concluded that incidental vocabulary learning or 'acquisition' achieves better results than intentional vocabulary learning. Zimmerman (1994) found that three hours a week of explicit vocabulary instruction plus some self-selected reading were more effective than reading alone. Paribakht and Wesche (1997) also found that reading plus explicit instruction led to superior gains over a period of three months. Parry $(1991,1993,1997)$ demonstrated that a combination of incidental and intentional learning of vocabulary during reading helped the overall development of both L2 vocabulary and academic success in $\mathrm{L} 2$.

\subsection{Explicit Teaching:}

Current research has suggested that it is worthwhile to add explicit vocabulary to the unusual inferring activities in the L2 classroom. Throughout the literature on L2 acquisition the following pedagogical themes emerge. 1 build large sight vocabulary, 2 integrate new words with old, 3 provide a number of encounters with words, 4 promote deep level processing, 5 facilitate imaging and concreteness, 6 use variety of techniques and 7 encourage independent learning strategies.

\section{Method}

\subsection{Sample Description}

The target population of the study are sixty students of first year Engineering in Sathyabama University, India. They were in the age group of $18-20$ with thirty six females and twenty four males. They completed plus two or intermediate, an eligibility examination for admission into engineering course. From a questionnaire given prior to the study it was found that all of them studied in English Medium except for one student who studied in Tamil medium.

\subsection{Need for the Study}

A questionnaire was given to find the needs of the participants. The findings show that the students have knowledge of the basic sentence structures and face lexical gaps in communication. Even in the suggestions given by the learners, the lexical gaps are evident. A vocabulary level test of Nation (1990) administered to the students revealed that most of the learners mastered the basic vocabulary but not other levels.

Instruments:

1. The instruments used in the study include pre and post-test vocabulary tests.

2. A questionnaire on the effectiveness of the strategy

The objective of conducting the pre-test was to compare the entry level of both groups before the strategy is tried out. The objective of post was to measure the effectiveness of the strategy from entry level to the exit level in both experimental and control groups. Care was taken to keep the format of two tests ( pre-test and post-test) and the degree 
of difficulty uniform in order to facilitate evaluation.

\section{Test Construction}

Pre-test

This test was largely based on the target words selected and learnt in the class. Since it was a traditional paper pencil test, the test evaluates the competence of the students on the target words. It included words selected for teaching apart from other words. The task types included defining the words, eliminating the meaning that does not belong to the group (odd word out), multiple choice, filling the blanks in the paragraph by contextual guessing and changing one form of the word into the other. The test was standardized after trying out on a sample group in the pilot study.

\subsection{Test Description}

The test consisted of the following items and the marks awarded for each item is given against it:

1. Defining the words -10 marks.

2. Find the odd word out-10 marks.

3. Multiple choice type-10 marks.

4. Filling blanks with appropriate words( cloze)- 10 marks.

5. Changing the word form as per the context in the sentence- 10 marks.

6. Scoring Procedure

All the questions were of objective type, so there were no complicationsin scoring. However in defining words, where even if learners used sentence in expressing the correct answer or even if spelling mistakes were made marks were given. In cloze test type only the correct word with correct spelling was given marks as the vocabulary knowledge of the students was tested.

To test the reliability and validity of the scores, the tests were evaluated by two people independently (a) investigator, (b) a lecturer in English.

\subsection{Post-test}

Objectives:

To measure the effectiveness of the strategy for both groups at the end of the course

To find whether the target were learnt or not

Test Construction: The test was repeatedly sampled with different students to standardize. The level of difficulty of pre-test and post-test was kept the same.

Test description: The items in the post test were similar to that of pre-test. The total marks and criteria of evaluation was same as that of pre-test.

Test Administration

The students were given pre-test before they were exposed to strategy and post -test after the strategy was carried out. The participants also showed vocabulary knowledge of the words based on Vocabulary Knowledge Scale ( VKS ) based on Paribhakt and Wesche's (1997)after the pre test. This was done to ensure that some of the words were new to the students. The new words that were included in the VKS scale include the words that leaner's learn incidentally by reading texts and other distracters.

\section{Material Selection}

Steps in Choosing the Target Words:

(i) Reading topic related short passages in the classroom not exceeding 350 words in the class.

(ii) Trying to find the form of the target words and guessing the other forms of the words.

(iii) Using the dictionary to cross check and correct the guessed 'meanings', definition and other forms of the word after reading.

(iv) Making a list of the new words by the students.

\section{The Classroom Procedures}

Since the strategy was carried out in the classroom, content based materials were used. In the traditional method the 
teacher gives out the meaning of words in the contexts. The experiment tries to find out whether reading comprehension exercises followed by focused vocabulary teaching is effective or reading the same comprehension passages followed by repeating the words once more in reading and correcting the errors is effective. In both strategies the intention of the scholar was to find out whether the retention for reading plus vocabulary group is better or reading only strategy if effective in the same duration of time. The materials were from the course book prescribed for the students. Extra tasks were created for the purpose of the experiment. Five reading passages from five units were used. For each passage words were chosen while doing reading tasks and activities were done in the next session.

Pre-reading Tasks: These tasks will present some of the essential vocabulary of the passage through the same but most likely different contextualisation. The context presented should be within the experience of the students and it should be both interesting and challenging so that the students are willing to talk.

3. Rationale: The success of a programme depends upon the student's participation. As any vigorous exercise is preceded by a warming up session, a teaching programme too should have a warm up session. This creates interest of the students in the task ahead.

\section{Preparation Prior to Classroom Teaching}

The plan was as follows. Before the students were asked to read the lesson silently, a warming up session was to be held. There were different opinions on introducing target words before reading. Since the advanced students should be exposed to the strategy of guessing from context, it was decided by the scholar not to explain target words before and during the session. So the meaning was given after guessing. Thus the pre-reading task prepared the students for leading them from known to unknown knowledge. The teacher then asked the students to read the first six paragraphs silently, without interrupting in the middle. Since the students were teenagers, one or two students who were not paying attention while others were reading. Once the reading was complete, the students were instructed to underline the new words as teacher informed the learners that an activity would be developed by the teacher using the words chosen by them, so as to make them learn more words. So the students actively took part in choosing the words and later explaining the passage paragraph wise, based on teachers' prompts and questions. As they explained paragraph wise, the teacher helped them in contextual guessing of unknown words. If they could not they were encouraged to refer to the dictionary. So in vocabulary tasks a need was created where the learners need to look into the dictionary to do certain tasks. While reading the passage and noting of target words took in 50 minutes, the activities for both groups were carried out in the next class after the completion of reading

Observations: The students showed great enthusiasm in noting the new words. This strategy was stimulating to the students as the material enabled them to share their experiences with their classmates. For example when the topic on how innovations taking place by happenstance, learners were sharing jokes on not getting disappointed if they invent a new thing in the chemistry lab. The new expression- 'environmental impact study' that they came across in the unit, made them discuss the impact of the expansion of IT corridor and consequent cutting down of trees. Some students' promptings made the teacher to have a discussion on how the trees can be saved by multi-national companies on IT corridor. It was also noticed that the target words were used by the students in their discussions. It was observed that more students started bringing dictionary to the class and dictionary use was gaining ground.

The students took the notes along with other error detection exercises. Some asked meanings for some words and the teacher gave the meanings. The class was teacher controlled as the task gave less scope for classroom interaction. Students weak in English concentrated more on correcting the grammatical errors with the help of their friends.

The control group students found the text interesting. It was challenging but not too frustrating to read. Since the teacher prepared well in advance, the teacher was able to facilitate learning by encouraging learners to guess in context. The teacher was flexible and the tasks permitted learners' autonomy especially when they students needed to develop story line using the target words. There were two categories of students in the class: those who were willing to talk and those who were not willing to talk- due to lack of self-confidence / fear / lack of interest. The teacher helped the students not willing to talk by encouraging them to explain the text and joining others in paraphrasing it. Some could answer easily, some required question prompts for them to find answers. All the students were actively engaged in the classroom activity. The teacher reinforced learning by writing the target words on the board. The activities that produced best results were negotiating the meaning by eliminating the other words, and meaning negotiated from several options. Both defining words and writing other forms of the word which involve usage of the word in the right form have not been found to be interesting to some students. Meanings were given by the teacher in the classroom in matching with the right word. The constraint was that not all students brought dictionary to the class. Since the investigator did not want to de-motivate the learners by insisting on a dictionary, allowed the students with dictionary to complete before giving the word meaning. In subsequent experiments, to overcome this difficulty clues for finding the words were introduced in the help box. Since not all words have fixed meaning different meanings were given in different contexts. Dictionary was used for changing one 
form into another. Many students actively used the dictionary and came up with different forms of nouns, adjectives etc, but the ones without a dictionary simply gave single word forms. Some of the students made spelling mistakes or even just added the suffixes given by the teacher. So the teacher had decided to teach affixes separately by playing a game of quiz in the class before taking up the next task. Students using the dictionary had few mistakes in using suffixes. Dictionary use made the learners discuss with each other. A group strategy of asking others for meaning is noticed.

\section{Hypothesis Evaluation}

Hypothesis No. 1: Post-test of Explicit Vocabulary Teaching group compared to their Pre- Test will show significant gains Pre- Test.

Hypothesis No 2:Post-test of Incidental Vocabulary Teaching group will have significant gains compared to their

Hypothesis No.3: There will be significant gains in the Post test of the Explicit vocabulary instruction group compared to the post test of Incidental Vocabulary Teaching group

The Main Hypothesis: Gains for the reading plus will be significant for Explicit Vocabulary Teaching group compared to Incidental Vocabulary Teaching group .

Null Hypothesis: Post-test of Explicit Vocabulary Teaching group will show significant gains compared to the PreTest of Explicit Vocabulary Teaching group

Statistical Analysis

An analysis of quantitative data obtained from the pre-test and the post-test is presented here.

1 Administering the Pre Test and Post Test

The pre-test and post-test were administered to both groups.

2 Analysis of the Scores

The pre test has five types of vocabulary tasks. The Post Test has five types of vocabulary tasks. In both test each task carry ten marks. The total marks for each test is 50 .

The computations carried out is as follows:

3 Statistical Concepts and Computations

The various summary statistics for both groups given below:

Table 1: Summary Statistic for Incidental reading group

\begin{tabular}{|c|c|c|}
\hline Description & Pre-Test & Post-test \\
\hline Mean & 21.53 & 28.25 \\
\hline S D & 6.97 & 8.23 \\
\hline CV & 32.38 & 29.14 \\
\hline N & 60 & 60 \\
\hline
\end{tabular}

Table 2: Summary Statistic for Explicit vocabulary teaching group

\begin{tabular}{|c|c|c|}
\hline Description & Pre-Test & Post-test \\
\hline Mean & 23.73 & 32.55 \\
\hline S D & 9.92 & 11.31 \\
\hline CV & 41.83 & 34.74 \\
\hline N & 66 & 66 \\
\hline
\end{tabular}

Note: ${ }^{\mathrm{S} D}=$ Standard Deviation $\mathrm{CV}=$ Co-efficient of Variation $\mathrm{n}=$ Number of Students

The means in the above tables reveal that Post -test measures are better than the Pre-Test measures for both the groups. 


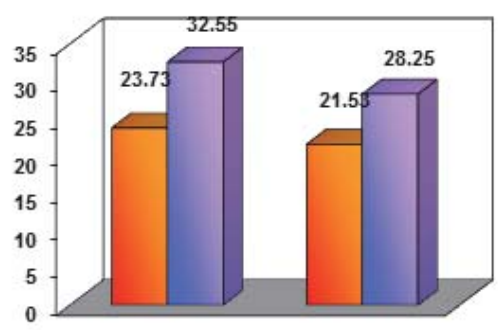

Figure 1: Representation of Mean of both the groups

To test the claims various statistical tests were performed and the results are given in the next section.

Assumptions for Statistical Tests

Assumption No. 1 There will be significant gains in the Posttest of Explicit vocabulary teaching group compared to their Pre- Test.

Assumption № 2

There will be gains in the Post-test of Incidental Vocabulary teaching group compared to their Pre- Test.

Assumption No.3

Given the same amount of time devoted to the two treatments, there will be significant gains in the Post test of the Explicit vocabulary instruction group compared to the Post test of Incidental Vocabulary Learning Group.

These assumptions are tested using $Z$ test for the significance of the sample means. In all the tests statistic

Zcal $=\sqrt{\frac{x_{1}-x_{2}}{\frac{\sigma_{1}^{2}}{n_{1}}+\frac{\sigma_{2}^{2}}{n_{2}}}}$

Where $x_{1}-x_{2}$ are the sample means. $x_{1} \rightarrow$ mean of sample I, $\mathrm{X}_{2} \rightarrow$ mean of sample II. $\sigma_{1}$ and $\sigma_{2}$ are the standard deviations of sample I \& II. $\mathrm{n}_{1}$ and $\mathrm{n}_{2}$ are the respective sample sizes.

Statistic Using Zcal Test

1. Pre Test of Control Group vs Pre- Test of Experimental Group

Null Hypothesis: Pre test means of both are not significant .

Alternate Hypothesis: The above two means are significant.

2 tail test $\propto=0.05 \overline{x_{1}}=23.73 \overline{\mathrm{x}_{2}}=21.53$

$\sigma_{1}=9.92 \sigma_{2}=6.97 \mathrm{n}_{1}=66 \mathrm{n}_{2}=60 \mathrm{Zcal}=1.42$

As Zcal is less than the critical value the null hypothesis is accepted.

Hence it is concluded that the level of both groups are identical.

2. Pre Test of Incidental Vocabulary learning group vs Post Test of Incidental Vocabulary learning group

Null Hypothesis: The Pre Test and Post Test Means of Incidental Vocabulary learning group are not significant .

Alternate Hypothesis: The above two means are significant.

1 tail test $\propto=0.05 \overline{X_{1}}=28.25 \overline{X_{2}}=21.53 \sigma_{1}=8.2 \sigma_{2}=6.97 n_{1}=60 n_{2}=60 \mathrm{Zcal}=4.822$

As Zcal is greater than the critical value the null hypothesis is rejected. the pre- test.

Hence it is concluded that there is gain in the level post- test of Incidental Vocabulary learning group compared to

3. Pre Test of Explicit Vocabulary Teaching Group vs. Post Test of Explicit Vocabulary Teaching Group

Null Hypothesis: The Pre Test and Post Test Means of Explicit Vocabulary Teaching Group are not significant

Alternate Hypothesis: The above two means are significant.

1 tail test

$\propto=0.05 \overline{\mathrm{x}_{1}}=32.55 \overline{\mathrm{x}_{2}}=23.73 \sigma_{1}=11.31 \sigma_{2}=9.92 \mathrm{n}_{2}=66 \mathrm{n}_{1}=66 \mathrm{Zcal}=4.76$

As Zcal is greater than the critical value the null hypothesis is rejected.

Hence it is concluded that there is significant gain in the level post test of Experimental group compared to the pre test.

4. Post Test of Incidental vocabulary learning group vs Post Test of Explicit Vocabulary Teaching Group 
Null Hypothesis: The Incidental vocabulary learning group and Explicit Vocabulary Teachinggroup Post test means are not significant .

Alternate Hypothesis: The above two means are significant.

1 tail test $\propto=0.05 \quad \overline{X_{1}}=32.55 \quad \overline{X_{2}}=28.23 \quad \sigma_{1}=11.31 \sigma_{2}=9.92$

$\mathrm{n}_{2}=60 \mathrm{n}_{1}=66 \mathrm{Zcal}=2.453$

As Zcal is greater than the critical value for the one tail test the null hypothesis is rejected.

Hence it is concluded that there is significant gain in the level post- test of Explicit Vocabulary teaching group compared to the pre- test.

Interpretations:

The main hypothesis is-

Given the same amount of time devoted to the two treatments, gains for the Explicit vocabulary instruction strategy will be significant compared to the Incidental vocabulary teaching strategy. From the above quantitative analysis it is clear that there is consistent improvement in the performance level of explicit vocabulary teaching group. So it can be interpreted that focused vocabulary teaching is more effective than the Incidental Vocabulary teaching strategy.

Strategy Evaluation

This section reports the evaluation of the strategy employed in the classroom for the explicit vocabulary teaching group. Feedback was obtained from the students through questionnaire and oral opinion.

Students' Feedback

Feedback from the students was obtained through questionnaire and opinionnaire to get information about the strategy, techniques and tasks used in the try out to experimental group. The outcomes were recorded qualitatively. Both objective and open ended questions were used. A full session was spent so that the students would be free and relaxed while offering comments and suggestions.

Analysis of Responses to Questionnaire:

An analysis of the responses to the questionnaire given to the students after the main study is presented along with the questionnaire and the responses.

Q1. The question relates to the topics chosen for the study-

Response: $70 \%$ found very interesting, $20 \%$ found interesting and $7.5 \%$ found average , $3 \%$ have no opinion

Q2. The question relates to the vocabulary activity carried out in the class was

Response: 80\% found very interesting, 12\% found interesting, 5\% found average, $3 \%$ not interesting.

Q3. The question relates to find if dictionary usage is encouraged by the tasks in the class, $51 \%$ highly agree, $25 \%$ agree, $16 \%$ no opinion $8 \%$ disagree.

Q4. The question seeks to find if repeating words in different types of activities in the class was useful- $92.5 \%$ strongly agreed, $5 \%$ responded agreed, the rest have no opinion. None opted for disagree.

Q5. The question relates to taking recommendation of the participants on the continuation of the strategy in other classrooms. An overwhelming 98\% responded yes, $2 \%$ left unanswered.

Q6. The questions seeks to find if the leaner's benefited by such activities in the class

Response : 98\% responded yes, $2 \%$ responded no.

Q7. Do you think the activities helped you to proceed with confidence in future to improve your vocabulary by repeating?

Response: 82\% $\%$ responded yes, 5\% responded no, $13 \%$ responded cannot say.

Q9. Did the class activity make you look for new words as you listen and read to English?

Response: $75 \%$ responded yes, $5 \%$ responded no, $20 \%$ responded cannot say.

Q10. Do you think the activity is different from what you have studied till XII?

Response: $85 \%$ responded yes, $15 \%$ responded no.

\section{Conclusion and Recommendations}

The students' participation is very important in the success of any programme. Compared to the incidental reading group, the students in explicit vocabulary instruction group had shown great enthusiasm in reading comprehension exercises as it was known to them all the words they choose would be used by the teacher to develop exercises in vocabulary tasks. However the students in incidental reading group were also prepared for the task ahead by engaging them in warm up session as warming up session creates interest in the learners for the tasks ahead

The following recommendations are made to those involved in improving the communicative competence of the learners, to the material developers and the teachers in the context of the study. It is necessary to develop strategies to 
improve the vocabulary of the learners by giving the learners autonomy in choosing the words from reading passages in the text books used in the classrooms. Since majority of the learners have exposure to basic knowledge of grammar in structural and functional patterns, vocabulary acquisition could be facilitated by the teachers by following the procedures suggested by the scholar. Word lists could be prepared from the reading comprehension exercises based on the words chosen by the learners from the reading passages given to them. Repetition of words for a minimum of seven times can be done through direct instruction in the classroom. Teachers should realise the usefulness of direct instruction based on the strategy suggested by the scholar, the classroom teaching becomes more interactive and learners find the sessions very interesting. Text book writers can provide supplementary books with the main book, where target words can be repeated in different task types.

\section{References}

Krashen ( 1989) retrieved online from http://www.sdkrashen.com/content/articles/comprehensible_output.pdf Laufer (1989). A Factor of Difficulty in Vocabulary Learning : deceptive Transparency. AlLA review. 6. pp.10-20 Lewis, M. (1993). 'The Lexical Approach'. England, Language Teaching Publication Nunan D (1988) Syllabus Design Oxford . OUP O'Dell, F. (1997).Incorporating Vocabulary into the Syllabus.In Schmitt and MacCarthy eds. (1997). pp. 258-278. Parry, K. (1991). Building A Vocabulary Through Academic Reading. TESOL Quarterly. Vol. 25, No. 4.

Paribakht, T.S. and M. Wesche. (1997). Vocabulary Enhancement Activities and Reading for Meaning in Second Language Acquisition. In Coady and Huckin (eds.), (1997). pp. 174-200.

Parry, K. (1991). Building A Vocabulary Through Academic Reading. TESOL Quarterly. Vol. 25, No. 4.

Sinclair, J. and Renouf, A. (1988) 'A lexical syllabus for language learning' in R. Carter and M. McCarthy (eds.) Vocabulary and Language Teaching, pp. 140-158. Harlow: Longman

Schmitt and MacCarthy ed., (1997). Vocabulary Description, Acquisition and Pedagogy. Cambridge, CUP.

Schmitt, N. (1997). Vocabulary Learning Strategies. in Schmitt and MacCarthy eds. (1997) pp.199-227.

Webb, S. (2005). Receptive and Productive Vocabulary Learning: The Effects of Reading and Writing on Word Knowledge. USA, SSLA, 27, pp.33-52.

Wilkins (1976) retrieved online @ http://ler.letras.up.pt/uploads/ficheiros/2771.pdf

\section{Appendixes 1}

Task Sheet for Explicit Vocabulary Teaching Group: Match the following words in A with their nearest meaning in B

A

\begin{tabular}{|c|c|l|}
\hline 1. & Serendipity & an attempt to change govt. with force \\
\hline 2. & innovate & a device that detects light \\
\hline 3. & revolution & to make changes/introduce new ideas \\
\hline 4. & happenstance & not very noticeable \\
\hline 5. & inconspicuous & chance \\
\hline 6. & amateur & making a very fine display or show \\
\hline 7. & spectacular & Obvious, clear \\
\hline 8. & sensors & to combine parts into a whole \\
\hline 9. & synthesize & to make a pleasant and unexpected discovery by chance \\
\hline 10. & dogged & Form an idea or plan in mind \\
\hline 11. & Conceived & An earlier example that is followed later \\
\hline 12. & Patent & with determination \\
\hline 13. & Precedent & To have a favourable effect on somebody \\
\hline 14. & impress & Showing care and effort in one's work \\
\hline 15. & diligent & a person takes part in sports not for money. \\
\hline
\end{tabular}

II. Rewrite the following sentences by using the words given in brackets $(20 \mathrm{~min})$ :

1. The invention of elastic rubber that is used to manufacture tires is made by chance. (serendipity).

2. The Processes of making changes and techniques in the textile industry is at full swing. (innovation)

A complete, dramatic change of method can be seen in printing techniques. (revolution).

I found the new colour by chance. (happenstance)

The small crack in the wall is not very obvious or noticeable. (inconspicuous)

The sport is open to leading persons interested in the game but no money is paid. (amateur)

The carnival had a fine display of fireworks. (Spectacle)

Security lights are fitted with devices that detect light, heat, pressure etc (sensors).

Two elements are combined into a whole by a chemical process (synthesize).

Their determination to defend the country is appreciable despite of adverse conditions (dogged defence)

11. The ancients had an idea that the world as being flat (conceived

12. His obvious dislike of the plan is understood by all. (patent)

13. There is no earlier decision that can be regarded as an example or rule to be followed to be followed now (Precedent).

14. We are enormously in respect of Ms. Smith ( impress).

15. He is a student who shows interest and takes effort in his studies (diligent). 
III. Write the other forms of the following words. Note that not all words change into other forms

\begin{tabular}{llll} 
Noun & $\begin{array}{l}\text { Verb } \\
\text { innovate } \\
\text { revolve }\end{array}$ & Adjective. & Adverb \\
\hline conspicuous & - & - & \\
$\overline{\text { Sensor }}$ & $\overline{\text { spectacular }}$ & \\
$\overline{\text { precedent }}$ & $\begin{array}{l}\text { synthesize } \\
\text { conceive }\end{array}$ & - & \\
\hline
\end{tabular}

IV. Fill the blanks in the following sentences with words given in Ex I, column A. Some word forms need to be changed. (the first letter is given as clue).

1. By h__ I met Dr. Madhavan Nair during my morning walk.

2. My brother is a d worker, for his efforts he is handsomely paid by the company.

3. I tried to i__ the people when I meet them first by right handshake, right eye contact and by remembering their names and pronouncing them correctly.

4. The www was found by s

5. There is no $p$ for this act of generosity in the history of mankind.

6. He has $\mathrm{p}$ rights to the new drug, though he is a_p_ liar.

7. As__ performance of lights and music was presented by the film actors of Hollywood.

8. This is an instrument with $\mathrm{s}$ __ which produces music based on the light rays.

9. He has pre-c-------notions about some people.

10. The military is putting up a d__ defense of the area inspite of adverse climatic conditions.

11. The scientists $\mathrm{s} \quad$ various elements while experimenting.

12. A great $\mathrm{r} \_$has come in the ideas of people due to globalisation.

13. His_ i__ ideas in the field of science are very much responsible for the transformation on of the company.

14. The a_ musician put up a good show.

15. The absence of the P.M in the Parliament was i___ as the Home Minister answered all queries of the opposition.

V. Try to write all the 15 words you have learnt is 2 minutes with correct spellings and write a paragraph using them;

VI. Use the following expressions in sentences of your own.

$\begin{array}{ll}\text { Spectacular Performance } & \text { Revolutionary ideas } \\ \text { Amateur artist } & \text { dogged defence } \\ \text { impressive appearance } & \text { diligent worker } \\ \text { pre-conceived notions } & \text { electronic sensors } \\ \text { synthesized rubber } & \text { patent rights. }\end{array}$

Appendixes - 2

\begin{tabular}{|c|c|c|c|}
\hline Theme/s & Target words & $\begin{array}{l}\text { Vocabulary task types for Explicit Vocabulary Teaching } \\
\text { Group }\end{array}$ & Tasks for Incidental Vocabulary Learning Group \\
\hline $\begin{array}{l}\text { 1. The Human Genome } \\
\text { Project } \\
\text { 2. Strokes of Genius }\end{array}$ & $\begin{array}{l}\text { 1. Serendipity } \\
2 \text { innovate } \\
\text { 3. revolution } \\
\text { 4. happenstance } \\
\text { 5. inconspicuous } \\
\text { 6. amateur } \\
\text { 7. spectacular } \\
\text { 8. sensors } \\
\text { 9. synthesize } \\
\text { 10. dogged } \\
\text { 11. Conceived } \\
\text { 12. Patent } \\
\text { 13. Precedent } \\
\text { 14. impress } \\
\text { 15. diligent }\end{array}$ & $\begin{array}{l}\text { 1. Matching the word in column A with their meaning in } \\
\text { Column B } \\
\text { 2. Rewriting the sentences by using the words given in } \\
\text { brackets: } \\
\text { 3. Writing the other forms of the words } \\
\text { 4. Filling the blanks in the sentences with given words } \\
\text { 5. Writing all the words in two minutes } \\
\text { 6. Writing a paragraph using the target words. } \\
\text { 7. Entering all the words in the space provided in the text } \\
\text { book }\end{array}$ & $\begin{array}{l}\text { 1. Discussing and writing answers to the questions that } \\
\text { include target words } \\
\text { 2. Encountering the target words in an 'Error Detection } \\
\text { Passage' }\end{array}$ \\
\hline
\end{tabular}

